\title{
Outcomes after liver transplantation in Korea: Incidence and risk factors from Korean transplantation registry
}

Jong Man Kim,*, Deok Gie Kim ${ }^{2, *}$, Jihyun $\mathrm{Kim}^{3}$, Keunsung Lee ${ }^{3}$, Kwang-Woong Lee ${ }^{4}$, Je Ho Ryư ${ }^{5}$ Bong-Wan Kim, Dong Lak Choi ${ }^{7}$, Young Kyoung You ${ }^{8}$, Dong-Sik Kim 9 , Yang Won Nah ${ }^{10}$, Koo Jeong Kang ${ }^{11}$, Jai Young Cho ${ }^{4}$, Geun Hong ${ }^{12}$, Hee Chul Yu ${ }^{13}$, Ju Ik Moon ${ }^{14}$, Dongho Choi ${ }^{15}$, Shin Hwang ${ }^{16}$, and Myoung Soo Kim ${ }^{17}$

${ }^{1}$ Department of Surgery, Samsung Medical Center, Sungkyunkwan University School of Medicine, Seoul; ${ }^{2}$ Department of Surgery, Yonsei University Wonju College of Medicine, Wonju; ${ }^{3}$ Novartis Korea Ltd., Seoul; ${ }^{4}$ Department of Surgery, Seoul National University College of Medicine, Seoul; ${ }^{5}$ Division of Hepato-Biliary-Pancreatic Surgery and liver Transplantation, Department of Surgery, Pusan National University Yangsan Hospital, Pusan National University School of Medicine, Yangsan; ${ }^{6}$ Department of Liver Transplantation and Hepatobiliary Surgery, Ajou University School of Medicine, Suwon; ${ }^{7}$ Department of Surgery, Catholic University of Daegu College of Medicine, Daegu; ${ }^{8}$ Department of Surgery, College of Medicine, The Catholic University of Korea, Seoul; ${ }^{9}$ Division of HBP Surgery \& Liver Transplantation, Department of Surgery, Korea University College of Medicine, Seoul; ${ }^{10}$ Department of Surgery, Ulsan University Hospital, University of Ulsan College of Medicine, Ulsan; "Department of Surgery, Dongsan Medical Center, Keimyung University School of Medicine, Daegu; ${ }^{12}$ Department of Surgery, Mokdong Hospital, Ewha Womans University School of Medicine, Seoul; ${ }^{13}$ Department of Surgery, Jeonbuk National University Medical School, Jeonju; ${ }^{14}$ Department of Surgery, Konyang University Hospital, Konyang University College of Medicine, Daejeon; ${ }^{15}$ Department of Surgery, Hanyang University College of Medicine, Seoul; ${ }^{16}$ Department of Surgery, Asan Medical Center, College of Medicine, University of Ulsan, Seoul; ${ }^{17}$ Department of Surgery, Yonsei University College of Medicine, Seoul, Korea

\section{Graphical Abstract}

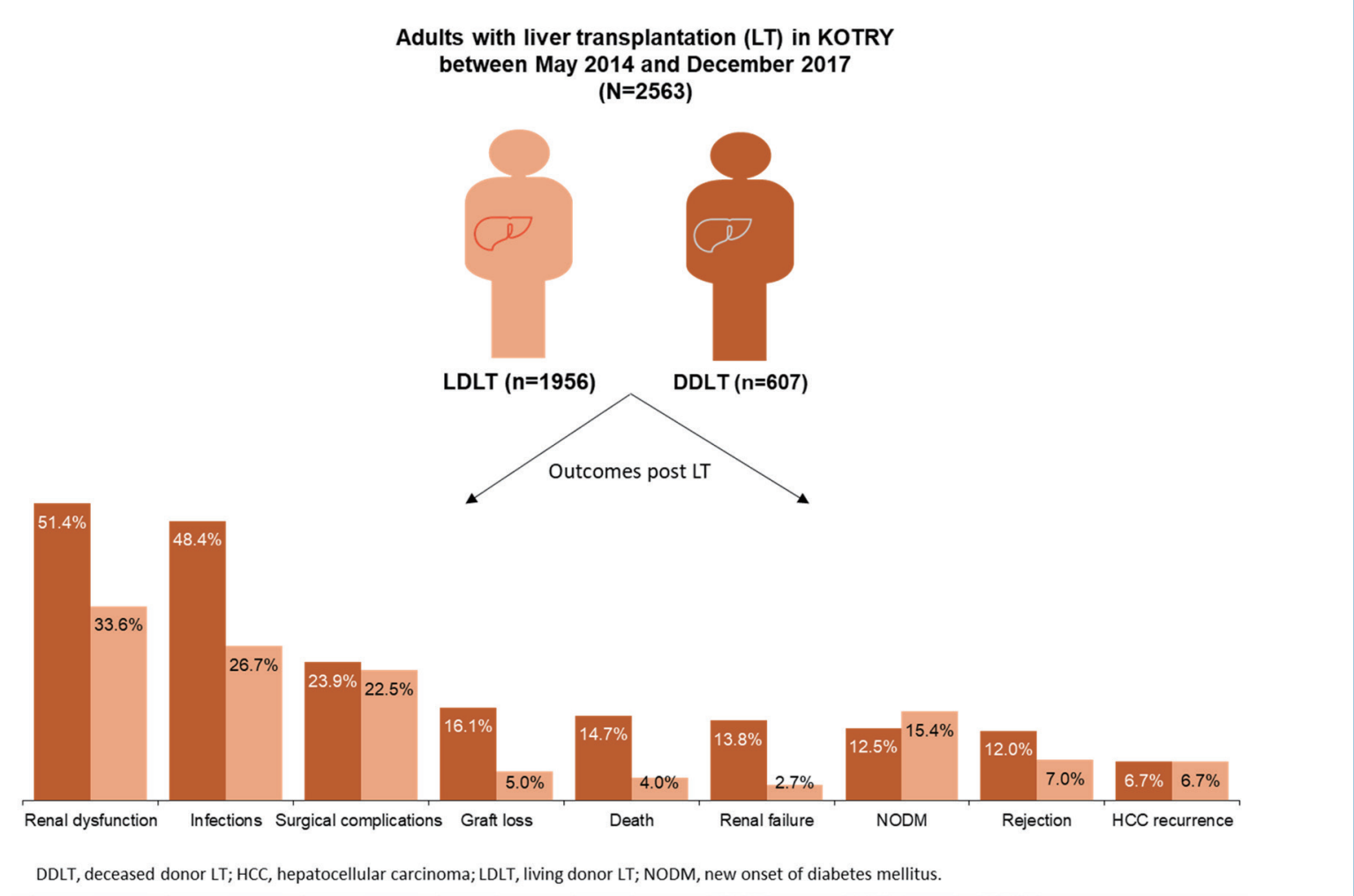

Copyright $(2021$ by Korean Association for the Study of the Liver

This is an Open Access article distributed under the terms of the Creative Commons Attribution Non-Commercial License (http://creativecommons.org/licenses/by-nc/3.0/) which permits unrestricted non-commercial use, distribution, and reproduction in any medium, provided the original work is properly cited. 
Background/Aims: To analyze the incidence and risk factors of outcomes after liver transplantation (LT) in the Korean population.

Methods: This study analyzed data from the liver cohort of Korean Organ Transplantation Registry (KOTRY) who had LT between May 2014 and December 2017. Study measures included the incidence of post-LT outcomes in recipients of living donor LT (LDLT) and deceased donor LT (DDLT). Cox multivariate proportional hazards model was used to determine the potential risk factors predicting the outcomes.

Results: A total of 2,563 adult recipients with $\mathrm{LT}(\mathrm{LDLT}, \mathrm{n}=1,956$; DDLT, $\mathrm{n}=607$ ) were included, with mean \pm standard deviation age of $53.9 \pm 8.9$ years, and $72.2 \%$ were male. The post-LT outcomes observed in each LDLT and DDLT recipients were death $(4.0 \%$ and $14.7 \%)$, graft loss $(5.0 \%$ and $16.1 \%)$, rejection $(7.0 \%$ and $12.0 \%)$, renal failure $(2.7 \%$ and $13.8 \%)$, new onset of diabetes (12.5\% and 15.4\%), and hepatocellular carcinoma (HCC) recurrence (both $6.7 \%)$. In both LDLT and DDLT recipients, the most common post-LT complications were renal dysfunction (33.6\% and 51.4\%), infection (26.7\% and $48.4 \%)$, and surgical complication (22.5\% and $23.9 \%$ ). Incidence of these outcomes were generally higher among recipients of DDLT than LDLT. Multivariate analysis indicated recipient age and DDLT as significant risk factors associated with death and graft loss. DDLT and ABO incompatible transplant were prognostic factors for rejection, and HCC beyond Milan criteria at pre-transplant was a strong predictor of HCC recurrence.

Conclusions: This study is a good indicator of the post-LT prognosis in the Korean population and suggests a significant burden of post-LT complications. (Clin Mol Hepatol 2021;27:451-462)

Keywords: Liver transplantation; Incidence; Risk factors; Renal insufficiency

\section{Study Highlights}

- In the Korean liver transplant population, incidence of graft loss, rejection and death were higher in recipients of deceased donor than living donor

- The most common outcomes occurring in more than $20 \%$ of recipients following LT were renal dysfunction, infection, and surgical complications

- The study highlights the burden of outcomes post LT, and identifies risk factors requiring special attention to improve prognosis

\section{INTRODUCTION}

Liver diseases are a public health problem worldwide and are highly prevalent in Asian countries.' In Korea, liver diseases have a high prevalence along with diabetes mellitus (DM), respiratory diseases, and hypertension. According to the Korea Statistics Office, liver diseases accounted for 13.3 deaths per 100,000 popula- tion in Korea, and ranked the seventh leading cause of death in 2017. ${ }^{2}$

Liver transplantation (LT) is the gold standard treatment for patients with end-stage liver disease. Since the first LT in Korea in 1988, the number of LT has increased dramatically over time. ${ }^{3}$ To meet such an increased demand, living donor LT (LDLT) has become an inevitable option as it shortens the waiting time and

\begin{abstract}
Abbreviations:
BMI, body mass index; DDLT, deceased donor liver transplantation; DM, diabetes mellitus; eGFR, estimated glomerular filtration rate; $\mathrm{HBV}$, hepatitis B virus; $\mathrm{HCC}$, hepatocellular carcinoma; KONOS, Korean Network for Organ Sharing; KOTRY, Korean Organ Transplantation Registry; LDLT, living donor liver transplantation; LT, liver transplantation; MELD, Model for End-stage Liver Disease; mTOR, mammalian target of rapamycin; NODM, new onset diabetes mellitus; SD, standard deviation
\end{abstract}

*Jong Man Kim and Deok Gie Kim equally contributed to manuscript as co-first author.

Editor: Moon Young Kim, Yonsei University Wonju College of Medicine, Korea

\section{Corresponding author: Myoung Soo Kim}

Department of Surgery, Yonsei University College of Medicine, 50-1 Yonsei-ro, Seodaemun-gu, Seoul 03722, Korea

Tel: +82-2-2228-2123, Fax: +82-2-313-8289

E-mail:ysms91@yuhs.ac

https://orcid.org/0000-0002-8975-8381

\section{Shin Hwang}

Department of Surgery, Asan Medical Center, College of Medicine, University of Ulsan, 88 Olympic-ro 43-gil, Songpa-gu, Seoul 0505, Korea Tel: +82-2-3010-3930, Fax: +82-2-3010-6701

E-mail: shwang@amc.seoul.kr

https://orcid.org/0000-0002-9045-2531

Received : Oct. 26, 2020/ Revised : Jan. 11, 2021 / Accepted : Jan. 29, 2021 
lowers the dropout rate in comparison to deceased donor LT (DDLT). ${ }^{4,5}$

According to the Korean Network for Organ Sharing (KONOS), the number of LT performed annually in Korea increased more than seven-fold between $2000(n=205)$ and $2019(n=1,579)$. Of the total LT procedures in 2019, LDLT accounted for 1,188 cases (75.24\%). ${ }^{6}$ The most common indication for LT was alcoholic liver disease (21.85\%), followed by hepatitis B virus (HBV; $18.43 \%)$, malignant neoplasms (17.10\%) and acute liver failure (4.05\%). ${ }^{6}$ The survival rate reported in 2019 for LDLT was $94.63 \%$ at 3 months, $90.41 \%$ at 1 year and $81.01 \%$ at 5 years post-transplant. DDLT showed a relatively lower survival rate of $82.24 \%, 77.31 \%$ and $68.46 \%$, respectively. ${ }^{6}$

Despite advancement in LT surgery techniques and post-LT management, complications after LT are still frequent. Graft loss, rejection, renal dysfunction, and new onset diabetes mellitus (NODM) are well-known post-LT complications. ${ }^{7}$ Recipient and donor age, gender, and blood group type matching have been identified as representative risk factors along with the need for appropriate management after LT to improve outcomes. ${ }^{8-12}$

Study on LT outcomes and associated risk factors in Korean population are still scarce. Identification of this data gap utilizing locally generated database will be worthy of understanding the current status of LT prognosis in Korea. The Korean Organ Transplantation Registry (KOTRY), which was established in 2014, is the first integrated national transplant registry in Korea that includes post-transplantation data from five solid organ transplantation cohorts, comprising of lung, kidney, heart, liver, and pancreas transplants. ${ }^{13}$

The objective of the present study was to investigate the incidence and risk factors of post-LT outcomes among LT recipients in Korea by leveraging the KOTRY registry database.

\section{MATERIALS AND METHODS}

\section{Study design and data source}

This study utilized data from the liver cohort of the KOTRY registry generated from 15 participating transplantation centers in 2015. These centers performed $81.5 \%$ of Korean LTs $(1,139 / 1,398)$ in 2015. ${ }^{4}$ The liver cohort of KOTRY, a web-based clinical research management system (iCReaT; http://icreat.nih.go.kr/, study number: (140015), collected data on both the recipient and living donor demographics, comorbidities, immunologic assessment and viral markers at enrollment. For deceased donors, donor profile on cause of brain death and cold ischemic time were collected at enrollment, and for LT recipients, additional data on laboratory assessment, immunosuppressant used, surgical complications, posttransplant outcomes and complications were collected at enrollment and at 1, 6, 12, 24, and 36 months post-transplant. The KOTRY registry was approved by the Institutional Review Boards of each participating center. All patients provided informed consent prior to their registration in the KOTRY database.

\section{Patient selection}

The study population consisted of patients included in the KOTRY registry who had LT between May 1, 2014 and December 31, 2017. The details of KOTRY design and patient enrollment have been described in previous reports. ${ }^{4,13} \mathrm{LT}$ recipients who had been followed up for at least 6 months post LT were included in the analysis. A total of 2,648 LT recipients were identified, of which 2,563 were adults and 85 were pediatrics. Given the heterogeneous characteristics of pediatric LT recipients, the sample size of pediatrics appeared too small to get statistically valid inferences. Thus, we analyzed the data on adults only.

\section{Study measures}

Study measures included recipient demographics (age, gender, body mass index [BMI]), comorbidities (hypertension and DM), underlying liver disease, Child-Turcotte-Pugh score and Model for End-stage Liver Disease (MELD) score for chronic liver disease or cirrhosis, urgent status in KONOS, ${ }^{14}$ donor type (LD or DD), donor demographics (age, gender, BMI), graft related variables (graft type, graft-recipient weight ratio and type of donor operation), ABO blood group compatibility, laboratory parameters, and type of immunosuppressant used. If hepatocellular carcinoma (HCC) was the underlying cause for LT, the pre-transplant HCC status including Milan criteria and liver cancer free (no viable tumor) state was additionally inspected. If the donor type was DD, cold ischemic time and macrovesicular steatosis in donor were also examined. All of these variables were assessed to identify the risk factors on post-LT outcomes.

\section{Post-LT outcomes}

The post-LT outcomes examined were overall survival, graft survival, malignancies (HCC, non-HCC, or cholangiocarcinoma), graft 


\section{CLLNCAL and MOLECULAR}

Table 1. Demographics and clinical characteristics of liver transplant recipients overall and by donor types

\begin{tabular}{|c|c|c|c|c|}
\hline Variable & Missing & Total $(n=2,563)$ & $\operatorname{LDLT}(n=1,956)$ & DDLT $(n=607)$ \\
\hline Age (years) & 0 & $53.9 \pm 8.9$ & $54.3 \pm 8.4$ & $52.6 \pm 10.3$ \\
\hline Sex, male & 0 & $1,850(72.2)$ & $1,441(73.7)$ & $409(67.4)$ \\
\hline $\mathrm{BMI} \geq 25 \mathrm{~kg} / \mathrm{m}^{2}$ & 2 & 937 (36.6) & $725(37.1)$ & $212(34.9)$ \\
\hline Underlying liver disease & 0 & & & \\
\hline Hepatitis B & & $1,433(55.9)$ & $1,184(60.5)$ & $249(41.0)$ \\
\hline Alcoholic & & $622(24.3)$ & $401(20.5)$ & $221(36.4)$ \\
\hline Hepatitis C & & $179(7.0)$ & $133(6.8)$ & $46(7.6)$ \\
\hline Cryptogenic & & $138(5.4)$ & $111(5.7)$ & $27(4.4)$ \\
\hline Others & & $191(7.5)$ & $127(6.5)$ & $64(10.5)$ \\
\hline Acute hepatitis & 0 & $109(4.3)$ & $52(2.7)$ & $57(9.4)$ \\
\hline Liver cancer & & $1,262(49.2)$ & & \\
\hline $\mathrm{HCC}$ & 0 & $1,229(48.0)$ & $1,056(54.0)$ & $173(28.5)$ \\
\hline $\mathrm{CCC}$ & & $11(0.4)$ & - & - \\
\hline Combined $\mathrm{HCC}+\mathrm{CCC}$ & & $20(0.8)$ & - & - \\
\hline Other malignancy & & $2(0.1)$ & - & - \\
\hline Pretransplant HCC status & 3 & & & \\
\hline Within Milan criteria & & $790(30.8)$ & $677(34.6)$ & $113(18.6)$ \\
\hline Beyond Milan criteria & & $212(8.3)$ & $176(9.0)$ & $36(5.9)$ \\
\hline No viable tumor & & $224(8.7)$ & $201(10.3)$ & $23(3.8)$ \\
\hline Incidental liver cancer & & $0(0.0)$ & $0(0.0)$ & $0(0.0)$ \\
\hline Hypertension & 0 & $454(17.7)$ & $363(18.6)$ & $91(15.0)$ \\
\hline Diabetes mellitus & 0 & $629(24.5)$ & $480(24.5)$ & $149(24.5)$ \\
\hline MELD score $(n=2,562)$ & 1 & & & \\
\hline$<15$ & & $1,319(51.5)$ & $1,234(63.1)$ & $85(14.0)$ \\
\hline $15-34$ & & $996(38.9)$ & $662(33.9)$ & $334(55.0)$ \\
\hline$\geq 35$ & & $247(9.6)$ & $59(3.0)$ & $188(31.0)$ \\
\hline CTP classification & 0 & & & \\
\hline$A(\leq 6)$ & & $742(29.0)$ & $723(37.0)$ & $19(3.1)$ \\
\hline B (7-9) & & $860(33.6)$ & $769(39.3)$ & $91(15.0)$ \\
\hline$C(\geq 10)$ & & $961(37.5)$ & $464(23.7)$ & $497(81.9)$ \\
\hline KONOS status & 0 & & & \\
\hline Score 1 & & $58(2.2)$ & $9(0.5)$ & $49(8.1)$ \\
\hline Score 2 & & $163(6.4)$ & $35(1.8)$ & $128(21.1)$ \\
\hline Score 3 & & $150(5.9)$ & $58(3.0)$ & $92(15.2)$ \\
\hline Score 4 & & $416(16.2)$ & $262(13.4)$ & $154(25.4)$ \\
\hline Score 5 & & $1,776(69.3)$ & 1,592 (81.4) & $184(30.3)$ \\
\hline ABO incompatible & 0 & $408(15.9)$ & $404(20.7)$ & $4(0.7)$ \\
\hline Graft type & 0 & & & \\
\hline Whole liver & & $577(22.5)$ & $0(0.0)$ & $577(95.1)$ \\
\hline Right liver graft & & $87(3.4)$ & $85(4.3)$ & $2(0.3)$ \\
\hline Left liver graft & & 1,899 (74.1) & $1,871(95.7)$ & $28(4.6)$ \\
\hline
\end{tabular}


Table 1. Continued

\begin{tabular}{|c|c|c|c|c|}
\hline Variable & Missing & Total $(n=2,563)$ & $\operatorname{LDLT}(n=1,956)$ & $\operatorname{DDLT}(n=607)$ \\
\hline Graft-recipient weight ratio for LDLT $<0.8$ & 33 & - & $159(8.3)$ & - \\
\hline Type of donor operation in LDLT $(n=1,956)$ & 0 & & & \\
\hline Minimal invasive surgery & & - & $388(19.8)$ & - \\
\hline Conventional, open & & - & $1,568(80.2)$ & - \\
\hline Use of steroids & & $2,288(89.3)$ & $1,767(90.3)$ & $521(85.8)$ \\
\hline Use of anti-metabolites & & $1,892(73.8)$ & $1,485(75.9)$ & $407(67.1)$ \\
\hline Use of mTOR inhibitors & & $282(11.0)$ & $212(10.8)$ & $70(11.5)$ \\
\hline
\end{tabular}

Values are presented as mean \pm standard deviation or number (\%).

LDLT, living donor liver transplantation; DDLT, deceased donor liver transplantation; BMI, body mass index; HCC, hepatocellular carcinoma; CCC, cholangiocarcinoma; MELD, Model for End-Stage Liver Disease; CTP, Child-Turocotte-Pugh; KONOS, Korean Network for Organ Sharing; mTOR, mammalian target of rapamycin.

rejection (acute or chronic), renal failure, renal dysfunction, infection, surgical complication and NODM.

Graft loss was defined as patient death or re-transplantation. Rejection was identified as diagnosed clinically or biopsy-proven. Renal failure was defined as initiation of dialysis or receipt of kidney transplantation and renal dysfunction was defined as the estimated glomerular filtration rate $(\mathrm{eGFR})<60 \mathrm{~mL} / \mathrm{min} / 1.73 \mathrm{~m}^{2}$. Infection was recorded when the causative pathogen was isolated and the patient was treated with antibiotics. Surgical complication was noted as one of the following: bleeding at operation site, intra-abdominal abscess, vascular stenosis or thrombosis (hepatic artery, portal vein stenosis or hepatic vein), biliary stricture, or biliary stenosis. NODM was defined as use of insulin or glucose lowering agent in patients who were non-diabetic before transplantation.

\section{Statistical analysis}

Continuous variables are expressed as mean \pm standard deviation (SD) or median (range: minimum, maximum) and categorical variables are expressed as counts and percentages.

Survival curves of LDLT and DDLT according to post-LT outcomes were estimated by the Kaplan-Meier method and tested using log-rank test. The censoring time was defined as the final documented date. The date of death with no evidence of outcomes was also considered censoring except in case of outcome death.

To assess the potential risk factors influencing the occurrence of post-LT outcomes, a separate univariate cox regression analysis was conducted with each variable as an independent predictor for each outcome. Significant variables in the univariate analysis
$(P<0.05)$ were included in a cox multivariate proportional hazards model to determine which factors independently predicted postLT outcomes and graft or patient survival. Results obtained from multivariate analysis were expressed as hazard ratio, 95\% confidence interval, and $P$-value. All tests were two-sided, and statistical significance was defined as $P<0.05$. All analyses were performed using SAS version 9.2 (SAS Institute, Cary, NC, USA).

\section{RESULTS}

\section{Baseline characteristics}

Two thousand five hundred sixty-three adult recipients were included in the analysis, with a mean follow-up duration of $14.7 \pm 10.6$ months based on the data collected until June 2018 . One thousand nine hundred fifty-six (76.3\%) recipients had LDLT and $607(23.7 \%)$ had DDLT. The mean \pm SD age of LDLT and DDLT recipients were $54.3 \pm 8.4$ and $52.6 \pm 10.3$ years, respectively. Recipient demographics and clinical characteristics according to donor type are summarized in Table 1.

Hepatitis B and alcoholic liver disease were the two most common underlying liver diseases among LDLT $(60.5 \%$ and $20.5 \%)$ and DDLT (41.0\% and $36.4 \%)$ recipients. Nearly half (49.2\%) of all recipients had liver cancer, and HCC was accountable for majority (97.4\%) of the neoplasms. Among recipients with HCC, about two-thirds (64.2\% in LDLT and $65.7 \%$ in DDLT) had pretransplant HCC within Milan criteria.

A higher proportion of DDLT than LDLT recipients had MELD score $\geq 35$ (31.0\% vs. $3.0 \%$ ), whereas more recipients of LDLT than DDLT had KONOS status score of $5(81.4 \%$ vs. $30.3 \%)$. Left 


\section{CLINCAL and MOLECULAA}

Volume_27 Number_3 July 2021

liver graft was most frequently used for LDLT (95.7\%), while the whole liver graft was commonly used in DDLT (95.1\%) (Table 1).

\section{Donor characteristics}

The mean age of overall LT donors was $35.3 \pm 14.0$ years and
$63.9 \%$ were male. A small proportion of donors (27.1\%) were overweight (BMI, $25-29 \mathrm{~kg} / \mathrm{m}^{2}$ ), and $7.2 \%$ had hypertension and $3.6 \%$ had DM. Living donors $(n=1,956)$ were relatives of recipients in most cases (85.9\%), and conventional operation (open surgery) was performed in $80.2 \%$ of them.

In deceased donors $(n=607)$, the principal cause of death was

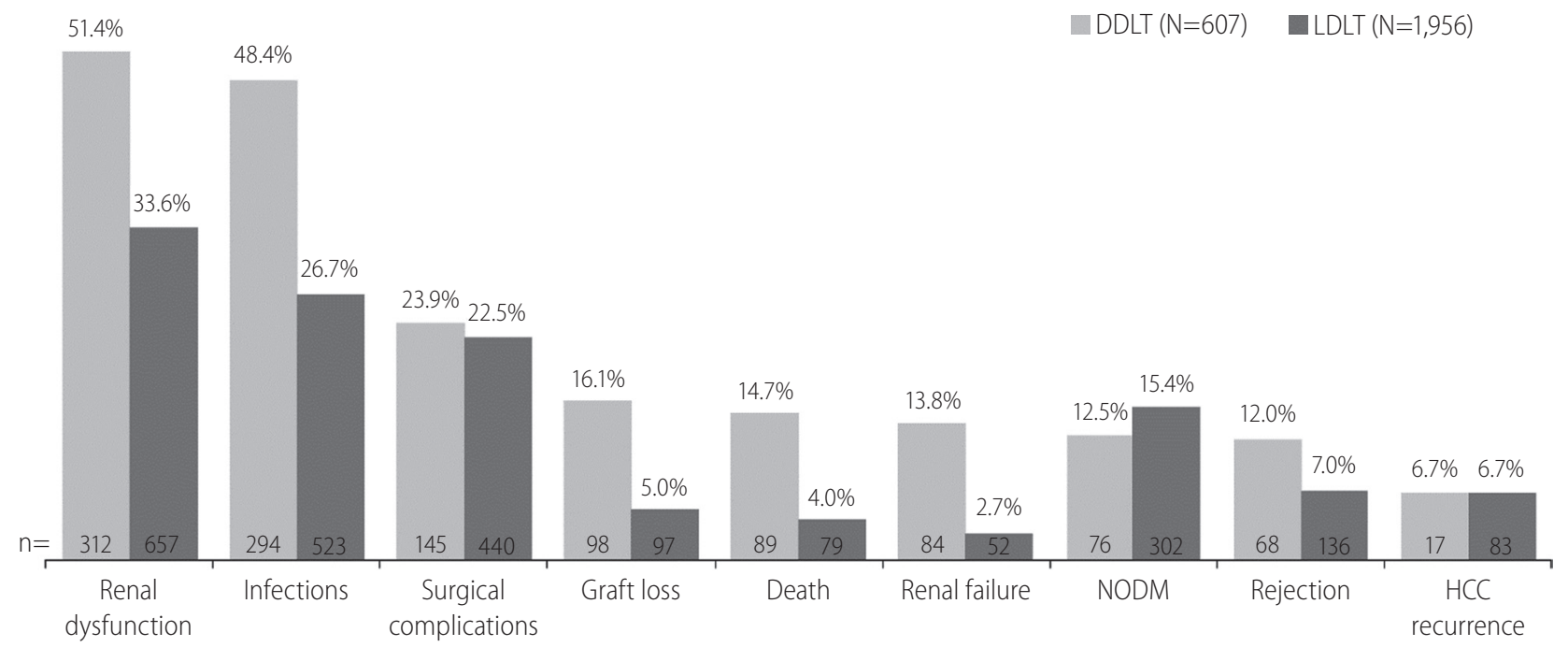

Figure 1. The incidence of post-transplantation outcomes among the recipients of liver transplantation by type of donors. $\mathrm{N}$ is the total number of recipients in each group; $\mathrm{n}$ is the number of recipients with a particular outcome. In DDLT group, $\mathrm{N}=568$ (for rejection) and N=254 (for HCC recurrence). In LDLT group, $\mathrm{N}=1,942$ for rejection and $\mathrm{N}=1,245$ for HCC recurrence. DDLT, deceased donor liver transplantation; LDLT, living donor liver transplantation; NODM, new onset of diabetes mellitus; HCC, hepatocellular carcinoma.

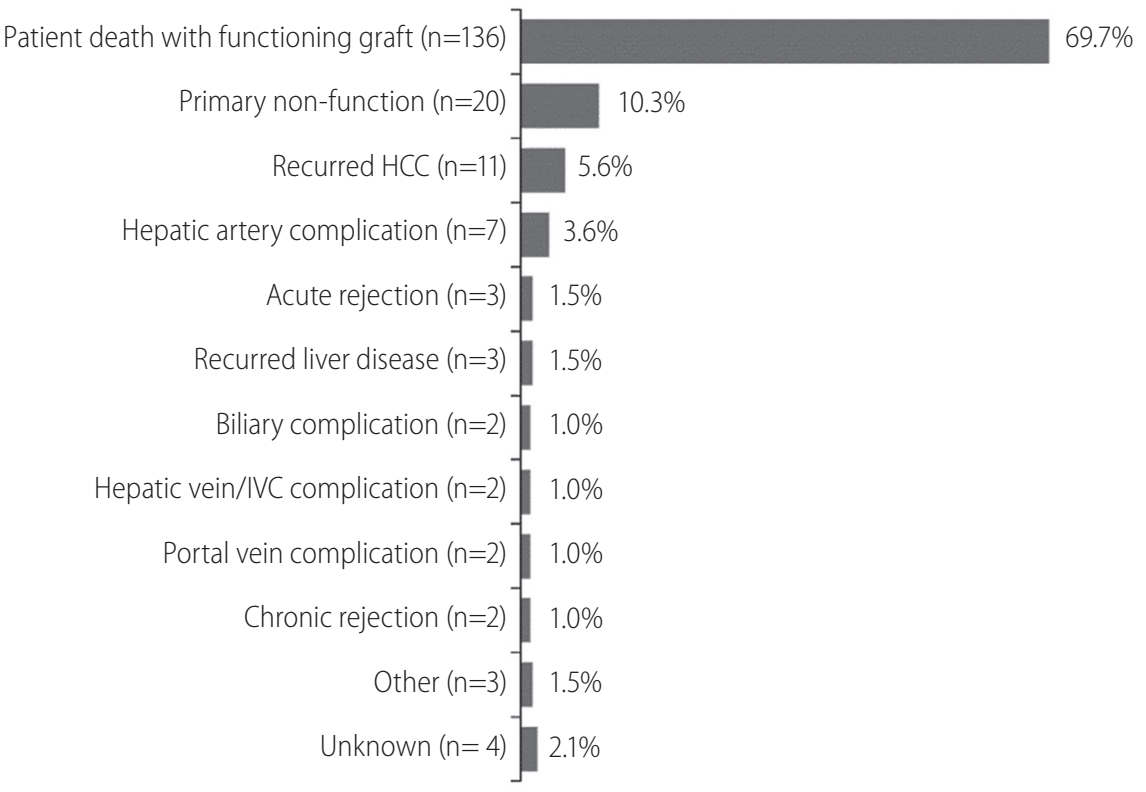

Figure 2. Causes of graft loss in adult patients with liver transplantation ( $N=195)$. $N$ is the total number of recipients with graft loss; $n$ is the number of recipients with a particular reason. HCC, hepatocellular carcinoma; IVC, inferior vena cava. 
progression of underlying disease (45.5\%), followed by trauma (32.0\%) and suicide (13.3\%). The most common etiological causes of death were subarachnoid hemorrhage (33.3\%), hypoxic

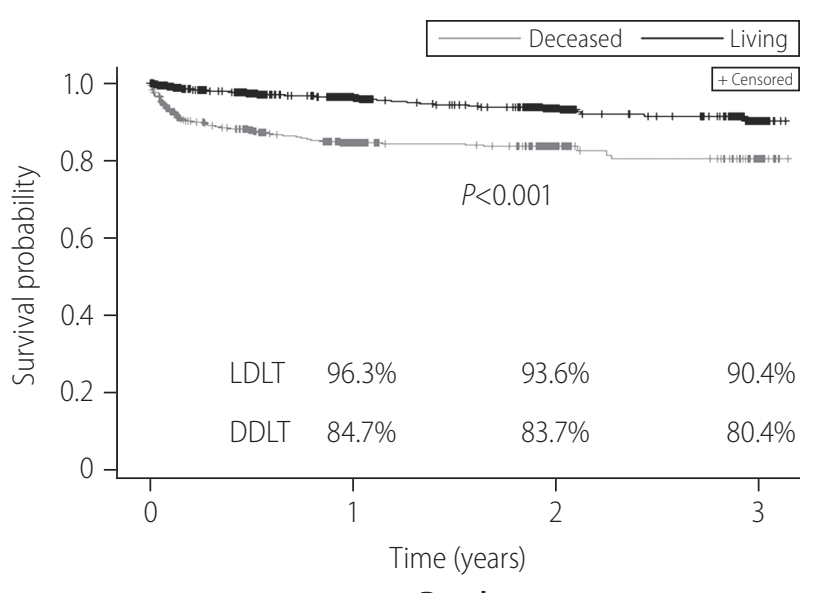

Death

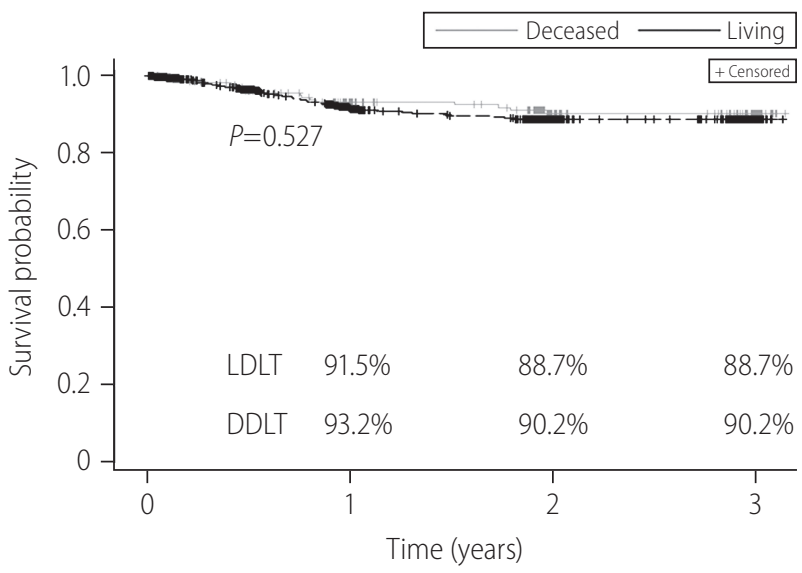

HCC recurrence

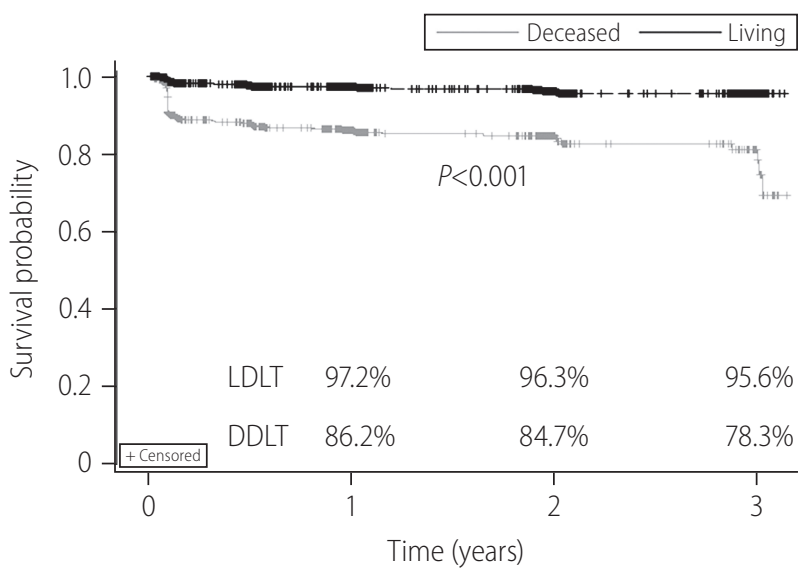

Renal failure damage (31.5\%), and intracranial hemorrhage (26.7\%). The mean cold ischemic time was $5.0 \pm 4.4$ hours. Macrovesicular steatosis was $<10 \%$ in majority $(84.9 \%)$ of the donors and $10-30 \%$ in

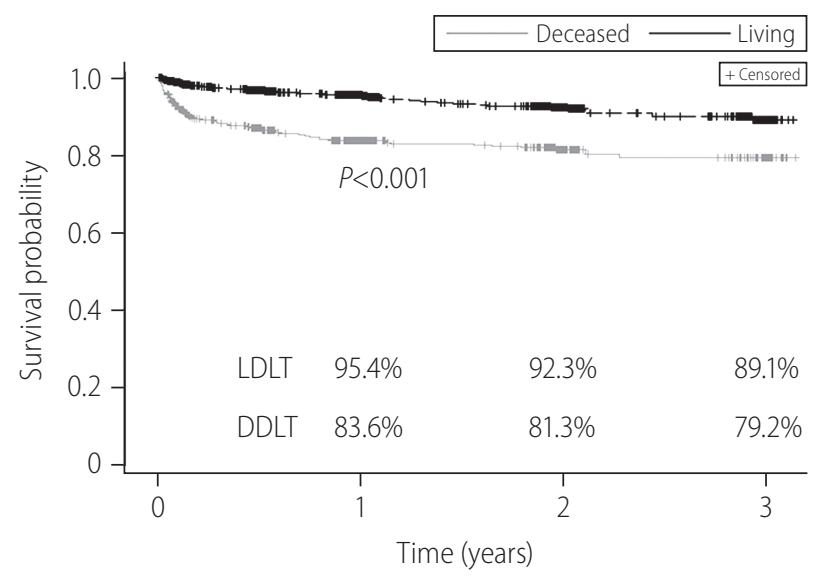

Graft loss

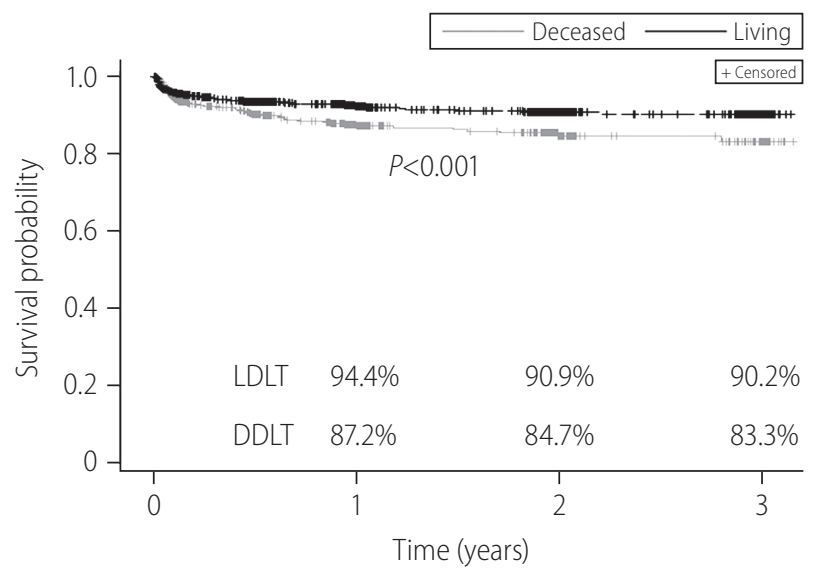

Rejection

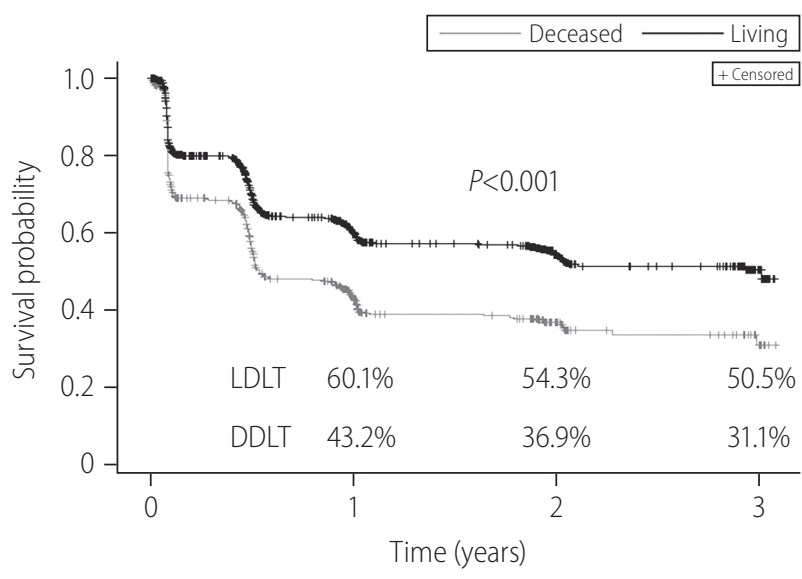

Renal dysfunction

Figure 3. Kaplan-Meier survival curve of post-transplantation outcomes in adult patients with liver transplantation. LDLT, living donor liver transplantation; DDLT, deceased donor liver transplantation; HCC, hepatocellular carcinoma; NODM, new onset of diabetes mellitus. 


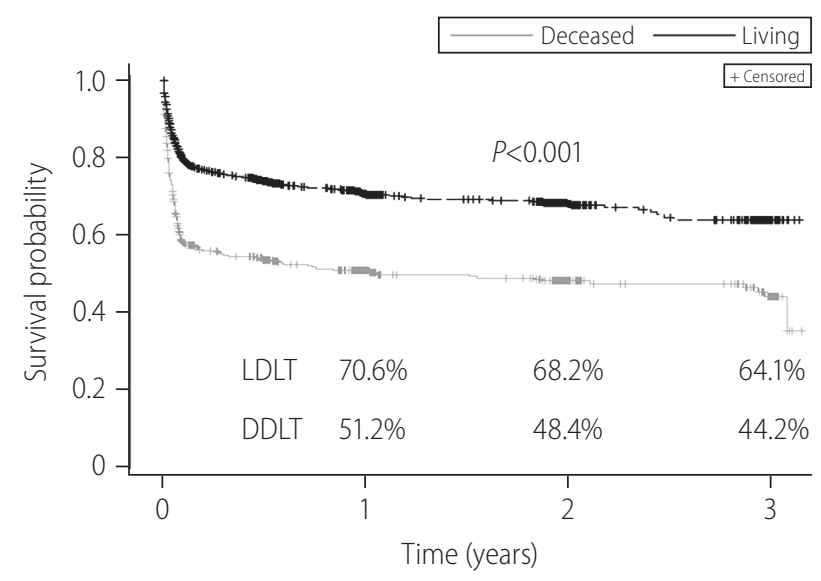

Infection

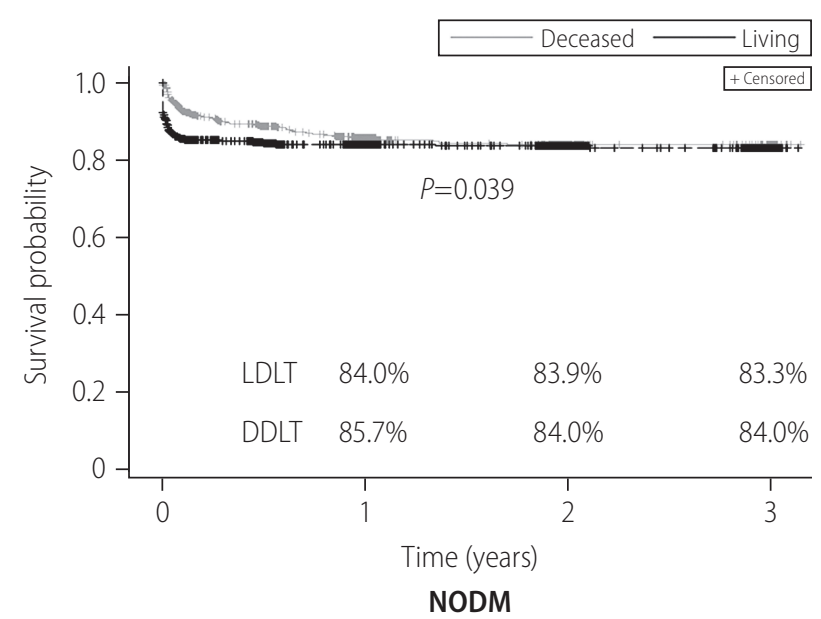

Figure 3. Continued.

$13.0 \%$ of the donors (data not shown and can be shared upon request to authors).

\section{Treatments after LT}

Induction of immunosuppression using steroids or basiliximab was performed in $89.4 \%$ and $77.1 \%$ of LT recipients, respectively. To maintain immunosuppression, most recipients (97.9\%) were given calcineurin inhibitors (e.g., cyclosporin and tacrolimus), followed by antimetabolite agents (e.g., azathioprine, mycophenolate mofetil, and mizoribine; $73.8 \%$ ) and mammalian target of rapamycin (mTOR) inhibitors (e.g., sirolimus and everolimus; $11.0 \%$ ).

For the prophylaxis of HBV post LT, almost all (98.7\%) recipients were prescribed anti-HBV-specific immunoglobulins either as monotherapy (34.1\%) or in combination with antiviral therapies (64.6\%).

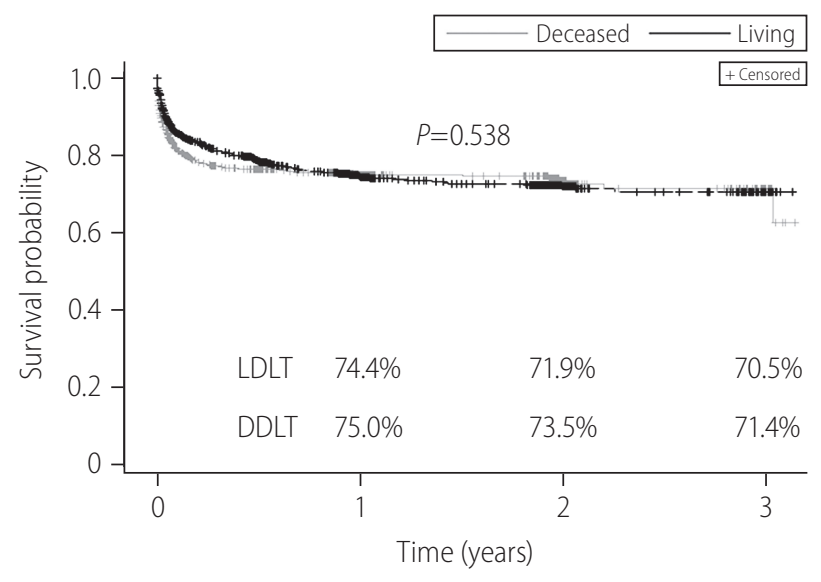

Surgical complications

\section{Outcomes after LT}

Incidence of death was $4.0 \%$ in LDLT group and $14.7 \%$ in DDLT group (Fig. 1). Graft loss was observed in $5.0 \%$ and $16.1 \%$ of LDLT and DDLT recipients, respectively. The leading causes of graft loss were death of patient with functioning graft (69.7\%), primary non-function of the graft (10.3\%) and recurrence of HCC (5.6\%) (Fig. 2).

Seven percent of LDLT and $12.0 \%$ of DDLT recipients experienced rejection. In both LDLT and DDLT recipients, the most common (>20\%) post-LT complications were renal dysfunction (33.6\% and $51.4 \%)$, infection $(26.7 \%$ and $48.4 \%)$, and surgical complication $(22.5 \%$ and $23.9 \%)$. Incidence of renal failure $(2.7 \%$ and $13.8 \%$ ). NODM (12.5\% and $15.4 \%$ ) and HCC recurrence (both $6.7 \%$ ) were generally low in both LDLT and DDLT groups. Except for NODM and HCC recurrence, the incidence rate of post-LT outcomes was higher in recipients of DDLT than LDLT (Fig. 1). 
Kaplan-Meier survival curves for each outcome are presented in Figure 3. Survival rate of LDLT recipients were significantly higher than DDLT recipients during the first 3 years post LT (3-year, 90.4\% vs. $80.4 \% ; P<0.001)$. Similar differences were observed for graft survival (3-year, $89.1 \%$ vs. $79.2 \% ; P<0.001)$ and rejection free survival (3-year, $90.2 \%$ vs. 83.3\%; $P<0.001$ ) between the two groups. Event-free survival rates for renal failure (3-year, $95.6 \%$ vs. $78.3 \%$; $P<0.001$ ), renal dysfunction (3-year, $50.5 \%$ vs. $31.1 \% ; P<0.001$ ) and infection (3-year, $64.1 \%$ vs. $44.2 \% ; P<0.001)$ were also significantly higher in LDLT recipients than DDLT. The survival distribution of patients not developing NODM were significantly different among LDLT and DDLT (3-year, 83.3\% vs. 84.0\%, $P=0.039$ ) and LDLT was higher than DDLT. No significant difference between LDLT and DDLT was observed for HCC recurrence free survival ( $P=0.527)$ and surgical complication $(P=0.538)$.

\section{Risk factors for post-LT outcomes}

In both univariate and multivariate analysis, increased recipient age (each $P<0.001$ ) and DDLT (each $P<0.001$ ) were significantly associated with increased risk of death. Recipient MELD score $\geq 35(P<0.001)$, underlying acute hepatitis $(P=0.004)$, donors' age $(P<0.001)$, and hypertension $(P=0.043)$ were identified as independent risk factors of death only in univariate analysis (Supplementary Table 1).

Multivariate analyses showed that increased recipient age $(P=0.012)$, DDLT $(P=0.001)$, underlying HCC $(P=0.011)$, and acute hepatitis $(P=0.044)$ were predisposing factors for graft loss after LT (Supplementary Table 2). HCC beyond the Milan criteria at pretransplant was the only significant factor identified to increase the risk of HCC recurrence post liver transplant $(P<0.001$; Supplementary Table 3). DDLT $(P=0.042)$ and ABO incompatible transplant $(P=0.002)$ were independent factors associated with increased risk of rejection (Supplementary Table 4). MELD score $\geq 35$ $(P<0.001)$ was a predictor of increased risk of renal dysfunction, along with increased recipient age $(P<0.001)$, DDLT $(P=0.004)$, hypertension $(P=0.007)$, and $\mathrm{DM}(P=0.011)$ in multivariate analysis (Supplementary Table 5). Multiple Cox regression analysis of risk factors for renal failure, infection, surgical complication and NODM are presented in Supplementary Tables 6-9.

\section{DISCUSSION}

This study showed the outcomes and their risk factor in patients who underwent LT. Renal dysfunction is the most common posttransplantation outcome in LDLT and DDLT, followed by infections, and surgical complications, while NODM, graft rejection, graft loss, HCC recurrence, and renal failure were other outcomes. With the exception of NODM, the incidence rate of these outcomes was greater among DDLT recipients compared with LDLT recipients. The age of recipient, MELD score, LDLT, underlying liver disease, Milan criteria were representative risk factors for the outcomes.

In the present study, incidence of death during follow-up duration was $6.5 \%$ for all recipients $(4.0 \%$ in LDLT and $14.7 \%$ in DDLT) and the survival rates at 1,2 , and 3 years after transplantation were notably higher in LDLT recipients than DDLT. The survival rates at 3-year observed in our study were consistent with recent studies showing superior survival in LDLT recipients than DDLT. ${ }^{15,16}$ In alignment with literature, our study also supports that recipient age is a risk factor for survival in LT recipients. ${ }^{15-17}$ We observed that LDLT was associated with lower risk of death compared to DDLT. Several studies have shown better survival outcomes among recipients with LDLT than DDLT, ${ }^{15,16,18}$ indicating this as a preferable option for LT. Evidence suggests that problem of organ shortage for transplantation in Asia has been successfully addressed by increasing the number of LDLT. However, in Western countries, the number of LDLTs have remained stagnant for over a decade, and the demand for DDLT continues to increase..$^{19}$ In Asian countries, high incidence of HCC and low organ donation rate from the deceased has evolved LDLT as a new emerging treatment modality for $\mathrm{HCC}^{20}$

We observed graft loss in $7.6 \%$ of our study population $(5.0 \%$ in LDLT and $16.1 \%$ in DDLT). The death of the LT recipient was the most common cause of graft loss, which is consistent with findings from literature. ${ }^{21} \mathrm{~A}$ study by Olthoff et al..$^{22}$ showed recipient age, hepatitis $C$ virus and $\mathrm{HCC}$ as the risk factors for graft loss. The study by Azzam demonstrated ABO-incompatible, the age and sex of the donor, hepatitis B and C virus, HCC as the independent risk factors for graft loss. ${ }^{17}$ Our study revealed that increased age of the recipient, DDLT, HCC, acute hepatitis, use of steroids, and use of anti-metabolites were risk factors for graft loss, which are in alignment with several studies published previously. ${ }^{22-24}$ Thus, it also becomes important that recipients' characteristics, including the underlying liver disease should be considered during management.

In this study, the recurrence of HCC was observed in $6.7 \%$ each of LDLT and DDLT recipients. A study by Sandhu et al. ${ }^{25}$ reported the low and similar rates of HCC recurrence at 3-year among re- 
cipients of LDLT and DDLT (10.7\% and 14.8\%). Previous research by Park et al. ${ }^{26}$ reported the low occurrence of de novo malignancies in $2.3 \%$ of Korean patients after a mean post-LT period of 41 months. Another study by Hong et al. ${ }^{27}$ reported the recurrence of $\mathrm{HCC}$ in $24.5 \%$ of the recipients at 5 years. Based on the Milan criteria, Lee et al. ${ }^{28}$ reported that the recurrence of HCC was $3.3 \%$ in patients within Milan and $29.4 \%$ in patients beyond Milan. Our study also supports this observation, as the multivariate analysis revealed that the risk of HCC recurrence was higher among patients with HCC beyond the Milan criteria compared to those within the criteria. In addition to the Milan criteria, other factors such as male gender, tumor size of more than $5 \mathrm{~cm}$, positive positron emission tomography scan, high serum alpha-fetoprotein level $(>1,000 \mathrm{ng} / \mathrm{mL}$ ), and poor histologic grade (Edmonson-Steiner grade III and IV) have also been suggested to be associated with higher recurrence of HCC in Korean studies. ${ }^{26-28}$

Despite the progress made in preoperative evaluation, surgical procedures, postoperative care, and immunosuppressant therapy, chronic renal disease remains a common complication post LT. ${ }^{29,30}$ Approximately $37.8 \%$ of all LT recipients $33.6 \%$ in LDLT and $51.4 \%$ in DDLT) in the present study were observed to have some degree of renal dysfunction post-transplantation, which is consistent with finding from earlier studies in Korea. ${ }^{31,32}$ A study by Lee et al. ${ }^{32}$ evaluating the early postoperative renal dysfunction in LDLT showed that $34.9 \%$ of recipients had renal dysfunction (defined as the creatinine level $\geq 1.5 \mathrm{mg} / \mathrm{dL}$ ) at 1-year post LT. In another study by Kim et al. ${ }^{31} 43.5 \%$ of the overall LT recipients were reported to have moderate renal dysfunction (defined as the $30 \leq$ eGFR $<60 \mathrm{~mL} / \mathrm{min} / 1.73 \mathrm{~m}^{2}$ ). The rate of renal dysfunction post-LT varies considerably among recipients in other countries, with $8.0 \%$ in Egypt, ${ }^{33} 48.0 \%$ in Spain, ${ }^{34}$ and $46.7 \%$ in Brazil. ${ }^{35}$ This disparity in post-LT renal dysfunction rates between these studies might arise from differences in pre-LT renal function status, source of graft (LDLT or DDLT), presence of diabetes/hypertension, postLT care, timing of kidney function monitoring, or definitions used for renal dysfunction. Thus, there is a need to standardize these definitions to enable better appraisal of studies worldwide.

The MELD scoring system has been reported as a validated tool that predicts the renal failure post $\mathrm{LT}^{36}$ In consistency with previous research, ${ }^{32,36}$ the pre-transplant MELD score $\geq 35$ was found to be a strong predictor of both renal failure and renal dysfunction in our study. Other significant risk factors such as increased recipient age and comorbid hypertension as predictor of renal dysfunction post LT were also in line with literature. ${ }^{29}$ The occurrence of renal dysfunction post LT leads to poor prognosis. We observed an increasing trend of renal dysfunction rates with longer followups $(44.2 \%, 50.2 \%$, and $54.8 \%$ at 1,2 , and 3 years, respectively). Since renal dysfunction can increase the need for renal replacement therapy and also increase the risk of cardiovascular diseases, preventive measures are warranted for better prognosis. $^{37,38}$

The rate of NODM in the current study was observed to be approximately $14.8 \%$. In a meta-analysis based on 56 studies, NODM was reported in $13.4 \%$ of patients following transplantation. ${ }^{39}$ We found that pre-transplant obesity (BMI $\left.\geq 25 \mathrm{~kg} / \mathrm{m}^{2}\right)$, use of steroids, and anti-metabolites were associated with a higher risk of NODM post LT. These results are in alignment with recent results published by KOTRY on NODM in the same population. ${ }^{40}$

In order to improve the outcomes after LT, appropriate surgical technique, donor-recipient matching and optimization of immunosuppressants is essential. Also, there is a need for further research on innovative management strategies such as machine perfusion, liver support device and tissue bioengineering. ${ }^{41}$

Our study has several limitations. First, this study was a retrospective study. We analyzed registry database and cautious interpretation is required since the severity of each patient in database is different and interventional adjustment was not possible. Second, the KOTRY is a relatively new registry with short follow-up period, so long-term outcomes, including median survival time, could not be assessed. Third, it was difficult to compare the effects of medications because the patient population using these medications was heterogeneous. The use of immunosuppressants as the risk factor for the occurrence of post LT outcomes could not be ascertained because patients' status were different for choosing an immunosuppressant agent which may lead to different outcomes. Lastly, in case of HCC recurrence, the use of mTOR inhibitors has the advantage of lowering the post-transplant malignancy compared with other immunosuppressants; however, the study showed that the use of an mTOR inhibitor at 6 months of transplantation poses a higher risk. Given that the order of the incidents could not be confirmed, the use of immunosuppressant was not considered as one of the risk factors.

Despite of these limitations, this study is a good indicator of the outcomes after transplantation in Korean LT recipients. Following $L T$, recipients of deceased donor reported higher rates of graft loss, rejection and death and the most frequent complications were renal dysfunction, infection, and surgical complications. Risk factors associated with poor outcomes warrant special attention to improve patient prognosis. 


\section{Authors' contributions}

JM Kim, DG Kim, MS Kim, and S Hwang had full access to all aspects of the study and takes responsibility for the integrity of the data and the accuracy of the data analysis. JM Kim and MS Kim participated in the research design. DG Kim, S Hwang, and MS Kim participated in the data acquisition. JM Kim and DG Kim participated in the statistical analysis. JH Kim contributed to study design, study execution, contributed to manuscript revision, and administrative support. KS Lee supported data analysis and study contributed to manuscript revision. The other authors participated in the performance of the research. MS Kim and S Hwang supervised the study process.

\section{Acknowledgements}

This research was supported by a fund by Research of Korea Centers for Disease Control and Prevention (2014-ER6301-00, 2014-ER6301-01, 2014-ER6301-02, 2017-ER6301-00, 2017ER6301-01, 2017-ER6301-02) and Novartis Korea Ltd., South Korea. Raju Gautam (Novartis Healthcare Pvt. Ltd, Hyderabad, India) provided medical writing assistance for the manuscript.

\section{Conflicts of Interest}

JM Kim, DG Kim and MS Kim received grants from Novartis Korea Ltd., South Korea for the conduct of this study. KS Lee employees of Novartis Korea Ltd., South Korea. JH Kim was an employee of Novartis Korea Ltd., South Korea at the time of conduct of this study, and left. Authors declare that they have no other conflicts of interest regarding the content of this manuscript.

\section{SUPPLEMENTARY MATERIAL}

Supplementary material is available at Clinical and Molecular Hepatology website (http://www.e-cmh.org).

\section{REFERENCES}

1. Wong MCS, Huang JLW, George J, Huang J, Leung C, Eslam M, et al. The changing epidemiology of liver diseases in the Asia-Pacific region. Nat Rev Gastroenterol Hepatol 2019;16:57-73.

2. Statistics Korea. Causes of death statistics in 2017. Statistics Korea web site, <https://www.kostat.go.kr/portal/korea/kor_nw/1/6/2/ index . board? bmode $=$ read\&bSeq $=\& a S e q=370710 \&$ page $\mathrm{No}=1 \&$ ro wNum $=10 \&$ navCount=10\&currPg $=\&$ searchlnfo=\&sTarget=title \&sT $x t=>$. Accessed 24 May 2019.

3. Lee SG, Moon DB, Hwang S, Ahn CS, Kim KH, Song GW, et al. Liver transplantation in Korea: past, present, and future. Transplant Proc 2015;47:705-708.

4. Lee JG, Lee KW, Kwon CHD, Chu CW, Kim BW, Choi DL, et al. Donor safety in living donor liver transplantation: the Korean organ transplantation registry study. Liver Transpl 2017;23:999-1006.

5. Park GC, Song GW, Moon DB, Lee SG. A review of current status of living donor liver transplantation. Hepatobiliary Surg Nutr 2016;5: 107-117.

6. Korean Network for Organ Sharing (KONOS). Organ transplantation statistics. 2019. KONOS web site, <http://konos.go.kr>. Accessed 26 Nov 2020.

7. Moreno R, Berenguer M. Post-liver transplantation medical complications. Ann Hepatol 2006;5:77-85.

8. Adam R, Karam V, Delvart V, O'Grady J, Mirza D, Klempnauer J, et al. Evolution of indications and results of liver transplantation in Europe. A report from the European Liver Transplant Registry (ELTR). J Hepatol 2012;57:675-688.

9. Bachir NM, Larson AM. Adult liver transplantation in the United States. Am J Med Sci 2012;343:462-469.

10. Durand F. How to improve long-term outcome after liver transplantation? Liver Int 2018;38 Suppl 1:134-138.

11. Durand F, Levitsky J, Cauchy F, Gilgenkrantz H, Soubrane O, Francoz C. Age and liver transplantation. J Hepatol 2019;70:745-758.

12. Sarkar M, Watt KD, Terrault N, Berenguer M. Outcomes in liver transplantation: does sex matter? J Hepatol 2015;62:946-955.

13. Yang J, Jeong JC, Lee J, Kim YH, Paik HC, Kim JJ, et al. Design and methods of the Korean Organ Transplantation Registry. Transplant Direct 2017;3:e191.

14. Lee J, Lee JG, Jung I, Joo DJ, Kim SI, Kim MS, et al. Development of a Korean liver allocation system using model for end stage liver disease scores: a nationwide, multicenter study. Sci Rep 2019;9:7495.

15. Gil E, Kim JM, Jeon K, Park H, Kang D, Cho J, et al. Recipient age and mortality after liver transplantation: a population-based cohort study. Transplantation 2018;102:2025-2032.

16. Humar A, Ganesh S, Jorgensen D, Tevar A, Ganoza A, Molinari M, et al. Adult living donor versus deceased donor liver transplant (LDLT versus DDLT) at a single center: time to change our paradigm for liver transplant. Ann Surg 2019;270:444-451.

17. Azzam A. Risk factors of hepatic graft failure, morbidity and mortality after living donor liver transplantation (LDLT): review article. Clin Res Trials 2018;4:1-11.

18. Zhu B, Wang J, Li H, Chen X, Zeng Y. Living or deceased organ donors in liver transplantation for hepatocellular carcinoma: a systematic review and meta-analysis. HPB (Oxford) 2019;21:133-147.

19. Jadlowiec CC, Taner T. Liver transplantation: current status and challenges. World J Gastroenterol 2016;22:4438-4445. 
20. Yoon YI, Lee SG. Living donor liver transplantation for hepatocellular carcinoma: an Asian perspective. Dig Dis Sci 2019;64:993-1000.

21. Bäckman L, Gibbs J, Levy M, McMillan R, Holman M, Husberg B, et al. Causes of late graft loss after liver transplantation. Transplantation 1993;55:1078-1082.

22. Olthoff KM, Abecassis MM, Emond JC, Kam I, Merion RM, Gillespie BW, et al. Outcomes of adult living donor liver transplantation: comparison of the adult-to-adult living donor liver transplantation cohort study and the national experience. Liver Transpl 2011;17:789797.

23. Gwiasda J, Schrem H, Klempnauer J, Kaltenborn A. Identifying independent risk factors for graft loss after primary liver transplantation. Langenbecks Arch Surg 2017;402:757-766.

24. Sharma R, Kashyap R, Jain A, Safadjou S, Graham M, Dwivedi AK, et al. Surgical complications following liver transplantation in patients with portal vein thrombosis--a single-center perspective. J Gastrointest Surg 2010;14:520-527.

25. Sandhu L, Sandroussi C, Guba M, Selzner M, Ghanekar A, Cattral $M S$, et al. Living donor liver transplantation versus deceased donor liver transplantation for hepatocellular carcinoma: comparable survival and recurrence. Liver Transpl 2012;18:315-322.

26. Park HW, Hwang S, Ahn CS, Kim KH, Moon DB, Ha TY, et al. De novo malignancies after liver transplantation: incidence comparison with the Korean cancer registry. Transplant Proc 2012;44:802-805.

27. Hong SK, Lee KW, Kim HS, Yoon KC, Yi NJ, Suh KS. Living donor liver transplantation for hepatocellular carcinoma in Seoul National University. Hepatobiliary Surg Nutr 2016;5:453-460.

28. Lee S, Ahn C, Ha T, Moon D, Choi K, Song G, et al. Liver transplantation for hepatocellular carcinoma: Korean experience. J Hepatobiliary Pancreat Sci 2010;17:539-547.

29. Bahirwani R, Reddy KR. Outcomes after liver transplantation: chronic kidney disease. Liver Transpl 2009;15 Suppl 2:S70-S74.

30. Wiesen P, Massion PB, Joris J, Detry O, Damas P. Incidence and risk factors for early renal dysfunction after liver transplantation. World J Transplant 2016;6:220-232.

31. Kim SG, Kim HJ, Lee JP, Lee SG, Kim YS, Ahn C, et al. Incidence and risk factors of renal dysfunction after liver transplantation in Korea. Transplant Proc 2004;36:2318-2320.

32. Lee SK, Park JB, Kim SJ, Choi GS, Kim DJ, Kwon CH, et al. Early postoperative renal dysfunction in the adult living donor liver transplantation. Transplant Proc 2007;39:1517-1519.

33. Abdel-Khalek EE, Alrefaey AK, Yassen AM, Monier A, Elgouhari HM, Habl MS, et al. Renal dysfunction after living-donor liver transplantation: experience with 500 cases. J Transplant 2018;2018:5910372.

34. Cabezuelo JB, Ramírez P, Ríos A, Acosta F, Torres D, Sansano T, et al. Risk factors of acute renal failure after liver transplantation. Kidney Int 2006;69:1073-1080.

35. Barreto $A G$, Daher EF, Silva Junior GB, Garcia JH, Magalhães $C B$, Lima JM, et al. Risk factors for acute kidney injury and 30-day mortality after liver transplantation. Ann Hepatol 2015;14:688-694.

36. Machicao VI, Srinivas TR, Hemming AW, Soldevila-Pico C, Firpi RJ, Reed Al, et al. Impact of implementation of the MELD scoring system on the prevalence and incidence of chronic renal disease following liver transplantation. Liver Transpl 2006;12:754-761.

37. Gonwa TA, Mai ML, Melton LB, Hays SR, Goldstein RM, Levy MF, et al. Renal replacement therapy and orthotopic liver transplantation: the role of continuous veno-venous hemodialysis. Transplantation 2001;71:1424-1428.

38. Weiner DE, Tighiouart $H$, Elsayed EF, Griffith JL, Salem DN, Levey $A S$, et al. The relationship between nontraditional risk factors and outcomes in individuals with stage 3 to 4 CKD. Am J Kidney Dis 2008;51:212-223.

39. Heisel 0 , Heisel R, Balshaw R, Keown P. New onset diabetes mellitus in patients receiving calcineurin inhibitors: a systematic review and meta-analysis. Am J Transplant 2004;4:583-595.

40. Man Kim J, Hwang S, Lee KW, Lee JG, Ryu JH, Kim BW, et al. Newonset diabetes after adult liver transplantation in the Korean Organ Transplantation Registry (KOTRY) study. Hepatobiliary Surg Nutr 2020;9:425-439.

41. Bodzin AS, Baker TB. Liver transplantation today: where we are now and where we are going. Liver Transpl 2018;24:1470-1475. 